\title{
ADHD and Its Comorbidities in College Students, with a Focus on Depression and Pathological Internet Use
}

\author{
Duk-Soo Moon, MD, PhD ${ }^{1}$, Na Ri Kang, MD, PhD ${ }^{1,2}$, Young-Eun Jung, MD, PhD ${ }^{1,2}$, \\ Moon-Doo Kim, MD, $\mathrm{PhD}^{1,2}$ \\ ${ }^{1}$ Department of Psychiatry, Jeju National University Hospital, ${ }^{2}$ Department of Psychiatry, Jeju National University School of Medicine, Jeju, \\ Korea
}

\begin{abstract}
Background: There is growing interest in adult attention-deficit hyperactivity disorder (ADHD) because many ADHD children have symptoms that last through adulthood, and adult ADHD has a high risk of comorbid mental disorders. This study examined the prevalence and comorbidities of adult ADHD, with a focus on depression and pathological internet use among Korean college students.

Methods: This study included 1358 college students, who were asked to complete self-reporting questionnaires on their characteristics, ADHD symptoms, and related clinical factors. The study analyzed associations between ADHD and depression, anxiety, pathological internet use, and problematic alcohol use.

Results: The prevalence rate of ADHD among college students was $5.7 \%$. A significant association was determined between ADHD symptoms and school satisfaction, depression, anxiety, and pathological internet use. Multivariate analysis showed that ADHD symptoms in college students were significantly associated with depression and pathological internet use.

Conclusion: The prevalence of ADHD among college students was similar to that of children and adolescents. Moreover, the risk of depression and pathological internet use was high in the ADHD group. Early screening and intervention for ADHD and comorbidities will be required to prevent the negative consequences of the condition and help students adapt in the future.
\end{abstract}

Keywords Attention-deficit hyperactivity disorder; College students; Depression; Pathological internet use

\section{INTRODUCTION}

Attention-deficit hyperactivity disorder (ADHD) is the most common psychiatric disease in childhood with symptoms of inattention, hyperactivity, and impulsivity. The prevalence is approximately $5 \%$ of children and $2.5 \%$ of adults [1]. In addition to school-age and adolescence, adult ADHD has attracted increasing interest because $50 \%$ to $65 \%$ of ADHD children have symptoms until adulthood and often have a Life-Long Condition $[1,2]$. Adult ADHD has a high risk of comorbid mental disorders, such as depression, anxiety, and substance abuse [3,4], and may be accompanied by Internet addiction $[5,6]$ and problems with adaptation to college $[7,8]$. In particular, Internet addiction is a problem observed frequently in adults (5.8\%) following adolescence $(12.5 \%)$ in a 2014 Korean survey [9]. This type of addiction is associated with negative mental health, such as ADHD, depression, and anxiety [10-12].

Few studies have examined adult ADHD in Korea, and surveys on the prevalence of ADHD symptoms in adults show inconsistent results, such as $1.1 \%, 2.8 \%$, and $7.6 \%$ [13-15]. In addition, previous Korean adult ADHD studies examined various mental pathologi-

Received September 29, 2020, Revised November 18, 2020, Accepted November 28, 2020

Correspondence: Young-Eun Jung, MD, PhD

Department of Psychiatry, Jeju National University Hospital, 15 Aran 13-gil, Jeju 63241, Korea

TEL +82-64-717-1234 FAX +82-64-717-1849 E-mail jyejye77@daum.net ORCID https://orcid.org/0000-0001-7608-0009

Copyright $@$ by Korean Society for Affective Disorders. All Rights reserved.

This is an Open Access article distributed under the terms of the Creative Commons Attribution Non-Commercial License (http://creativecommons.org/licenses/ by-nc/4.0/) which permits unrestricted non-commercial use, distribution, and reproduction in any medium, provided the original work is properly cited. 
cal relationships, such as depression, anxiety, bipolar spectrum disorder, alcohol problems, but did not include pathological internet use, which has recently emerged as a problem $[13,14,16]$, or had limitations with small numbers of participants [17]. Given the coexisting mental illness and adaptation problems of ADHD, awareness and intervention of adult ADHD are needed. Young adult college students are a good target for early detection and intervention of adult ADHD. This study examined the prevalence of ADHD, the coexisting psychopathology, and the pathological internet use among Korean college students.

\section{MATERIALS AND METHODS}

\section{Participants}

In this study, letters were sent to colleges located in the Jeju Special Self-Governing Province, Korea, including a statement explaining the aims of the study. Four colleges agreed to participate and written informed consent was received from 1,416 college students aged 18 years or older. The student completed a self-administered questionnaire. Ten research assistants, including social workers and psychiatric nurses, conducted this study. The participants were given an explanation about the purpose of the survey, and directions were provided to help the participants answer the survey questionnaires, which included several self-report screening instruments. The institutional review boards of Jeju National University Hospital approved this study (IRB No. JEJUNUH 2018-10-009-001). Twenty-six subjects were excluded because their responses were incomplete, leaving 1,358 subjects for the final analysis.

\section{Assessment}

A self-report questionnaire was used to obtain information on the sociodemographic and clinical symptom related variables, which included age, sex, parental marital status, self-reported socioeconomic status (SES), school records, satisfaction with school life, and previous history of psychiatric disorders.

The Adult ADHD Self-Report Scale-Version 1.1 (ASRSv1.1) Screener was used to screen adults with ADHD. The ASRSv1.1 Screener is a subgroup of the symptoms checklist of the 18-question World Health Or- ganization ASRS, which evaluates the frequency of all 18 Diagnostic and Statistical Manual of Mental Disorders, Text Revision, 4th edition, Criterion A symptoms of ADHD. Each item examines how often a particular symptom of ADHD occurred over the past six months. The items were rated on a five-point scale, with the following response options: never (0), rarely (1), sometimes (2), often (3), and very often (4). Scores of 14 and above indicated the presence of ADHD symptoms in adults $[18,19]$.

The Patient Health Questionnaire-9 (PHQ-9) and Generalized Anxiety Disorder Screener (GAD-7) was used to collect information on depression and anxiety. The PHQ-9, which is a tool for measuring depressive symptoms and severity over the past two weeks, was also used to identify depression [20]. The PHQ-9 was composed of nine items rated from 0 (not at all) to 3 (having the symptoms nearly every day). The scores for each item were summed to produce a total depression severity score (range: $0-27$ ). The Korean version of the PHQ-9 was reported to have high internal consistency (Cronbach's $\alpha=0.831$ ). A total score of the PHQ-9 score was $\geq 10$ indicated depression [21]. GAD-7 is a one-dimensional instrument designed to detect anxiety symptoms. The scores of each item range from 0 (not at all) to 3 (nearly every day). The total scores can range from 0 to 21 . A cutoff score of 10 indicated significant anxiety symptoms [22].

The Alcohol Use Disorder Identification Test-Alcohol Consumption (AUDIT-C) instrument was administered to assess the severity of alcohol use. A cutoff score of eight indicated significant alcohol use [23]. The SelfReport Scale for Measuring Behavioral Symptoms of Adults' Pathological Internet Use was employed to screen for pathologic internet use. This scale is a screening tool for internet addiction among adults and is composed of 20 items. The scale has high internal consistency (Cronbach's $\alpha=0.87$ ) and consists of four factors toward virtual reality, distraction and mood alteration, tolerance and preoccupation, and feeling guilty for Internet use. A cutoff score of 43 indicated pathological internet use [24].

\section{Statistical analysis}

The Pearson chi-square test and independent t-test were used to compare the proportions and means of the independent variables versus the dependent variables. 
Univariate analysis examined the associations between the independent variables and ADHD. A logistic regression model was used to assess the independence of the factors potentially associated with ADHD on univariate analyses. The odds ratios (ORs) and 95\% confidence intervals (CIs) were derived from a series of logistic regression analyses. All statistical analyses used PASW Statistics for Windows, Version 18.0 (SPSS Inc., Chicago, IL, USA). An alpha level of 0.05 was considered significant.

\section{RESULTS}

Of the 1,358 participants, 553 men (40.7\%) and 805 women (59.3\%) were included; $51.5 \%, 40.1 \%$, and $8.4 \%$ were under the age of 20, between 21 and 24 years, and older than 25 years, respectively. ADHD symptoms were found in $5.7 \%(n=78)$ of all participants. Significant dif- ferences in satisfaction with school life were observed between the Non-ADHD and ADHD groups $(\mathrm{p}<0.001)$. The ADHD group reported more dissatisfaction with school life (24.4\%) than the non-ADHD group (10.2\%). Age, gender, parental marital status, and self-reported SES were not related to ADHD symptoms (Table 1).

Previous psychiatric diagnoses were reported by 67 (4.9\%) of the participants. The PHQ-9, GAD-7, and pathological internet use scores were significantly higher in the ADHD group than the non-ADHD group $(\mathrm{p}<0.001)$. One hundred fifty-one college students (11.1\%) had positive PHQ-9 scores, indicating the presence of depression. Similarly, 81 college students $(6.0 \%)$ had GAD-7 scores suggesting anxiety symptoms. The ADHD group was five times more likely to have depression ( $48.7 \%$ vs. $8.8 \%)$ and anxiety (29.5\% vs. $4.5 \%)$ than the non-ADHD group.

Depression, anxiety, and pathological internet use were significantly higher in the ADHD group than the

Table 1. Characteristics among study population with and without ADHD symptoms

\begin{tabular}{|c|c|c|c|}
\hline Variable & Non-ADHD $(n=1,280)$ & $\mathrm{ADHD}(\mathrm{n}=78)$ & $p$-value \\
\hline Age (y) & $20.9 \pm 2.6$ & $20.8 \pm 1.9$ & 0.521 \\
\hline$\leq 20$ & $658(51.4)$ & $41(52.6)$ & 0.974 \\
\hline $21-24$ & $542(42.3)$ & $32(41.0)$ & \\
\hline$\geq 25$ & $80(6.3)$ & $5(6.4)$ & \\
\hline Gender & & & 0.769 \\
\hline Men & $520(40.6)$ & $33(42.3)$ & \\
\hline Women & $760(59.4)$ & $45(57.7)$ & \\
\hline Parental marital status & & & 0.956 \\
\hline Married & $999(78.0)$ & $62(79.5)$ & \\
\hline Separated & $211(16.5)$ & $12(15.4)$ & \\
\hline Divorced & $70(5.5)$ & $4(5.1)$ & \\
\hline Self-reported SES & & & 0.771 \\
\hline High & $247(19.3)$ & $14(17.9)$ & \\
\hline Middle & $886(69.2)$ & $53(67.9)$ & \\
\hline Low & $147(11.5)$ & $11(14.1)$ & \\
\hline Academic achievement & & & $0.024 \star$ \\
\hline Above average & $381(29.8)$ & $20(25.6)$ & \\
\hline Average & $691(54.0)$ & $36(46.2)$ & \\
\hline Below average & $208(16.3)$ & $22(28.2)$ & \\
\hline School Satisfaction & & & $<0.001 *$ \\
\hline Above average & $583(45.5)$ & $26(33.3)$ & \\
\hline Average & $567(44.3)$ & $33(42.3)$ & \\
\hline Below average & $130(10.2)$ & $19(24.4)$ & \\
\hline
\end{tabular}

Values are presented as mean \pm standard deviation or number (\%).

ADHD, attention-deficit hyperactivity disorder; SES, socioeconomic status.

*Statistically significant difference. 
non-ADHD group. Moreover, the incidence of problematic alcohol use was higher in the ADHD group than the non-ADHD group but the difference was not significant (37.2\% vs. $30.9 \%, \mathrm{p}=0.242$ ) (Table 2 ).

Table 3 lists the multivariate associations between the independent variables and ADHD. After adjusting for age, sex, and SES, the results showed that previous psychiatric diagnoses (OR, 2.990; 95\% CI, 1.315-6.800; $\mathrm{p}=0.009$ ), presence of depression (OR, 4.485; 95\% CI, $2.384-8.436 ; \mathrm{p}<0.001)$, and presence of pathological internet use (OR, 2.881; 95\% CI, 1.698-4.890; $<<0.001)$ were related to ADHD symptoms.

Table 2. Mental health related conditions with and without ADHD symptoms

\begin{tabular}{|c|c|c|c|}
\hline Variable & Non-ADHD $(n=1,280)$ & $\mathrm{ADHD}(\mathrm{n}=78)$ & $p$-value \\
\hline Previous psychiatric diagnosis & & & $<0.001 \star$ \\
\hline Yes & $51(4.0)$ & $16(20.5)$ & \\
\hline \multicolumn{4}{|l|}{ Depression } \\
\hline PHQ-9 positive & $113(8.8)$ & $38(48.7)$ & $<0.001 \star$ \\
\hline PHQ-9 score & $3.7 \pm 4.0$ & $10.2 \pm 6.2$ & $<0.001 \star$ \\
\hline \multicolumn{4}{|l|}{ Anxiety } \\
\hline GAD-7 positive & $58(4.5)$ & $23(29.5)$ & $<0.001 *$ \\
\hline GAD-7 score & $2.6 \pm 3.3$ & $7.3 \pm 5.5$ & $<0.001 \star$ \\
\hline \multicolumn{4}{|l|}{ Problematic internet use } \\
\hline Problematic internet use positive & $191(14.9)$ & $35(44.9)$ & $<0.001 \star$ \\
\hline Problematic internet use score & $30.6 \pm 10.3$ & $40.7 \pm 11.9$ & $<0.001 *$ \\
\hline \multicolumn{4}{|l|}{ Problematic alcohol use } \\
\hline AUDIT-C positive & $395(30.9)$ & $29(37.2)$ & 0.242 \\
\hline AUDIT-C mean & $5.4 \pm 3.2$ & $5.8 \pm 3.6$ & 0.210 \\
\hline
\end{tabular}

Values are presented as number (\%) or mean \pm standard deviation.

ADHD, attention-deficit hyperactivity disorder; PHQ-9, Patient Health Questionnaire-9; GAD-7, Generalized Anxiety Disorder Screener; AUDIT-C, Alcohol Use Disorder Identification Test-Alcohol Consumption.

*Statistically significant difference.

Table 3. Factors associated with ADHD symptoms

\begin{tabular}{|c|c|c|}
\hline \multirow{2}{*}{ Variable } & \multicolumn{2}{|c|}{ Non-ADHD vs. ADHD group } \\
\hline & OR $(95 \% \mathrm{Cl})$ & $p$-value \\
\hline Previous psychiatric diagnosis & $2.990(1.315-6.800)$ & $0.009 *$ \\
\hline Problematic alcohol use & $1.386(0.817-2.351)$ & 0.227 \\
\hline Problematic internet use & $2.881(1.698-4.890)$ & $<0.001 *$ \\
\hline Depression & $4.485(2.384-8.436)$ & $<0.001 *$ \\
\hline Anxiety & $1.912(0.927-3.945)$ & 0.080 \\
\hline \multicolumn{3}{|l|}{ Academic achievement } \\
\hline Above average & Reference & \\
\hline Average & $0.905(0.482-1.699)$ & 0.756 \\
\hline Below average & $1.812(0.887-3.702)$ & 0.103 \\
\hline \multicolumn{3}{|l|}{ School Satisfaction } \\
\hline Above average & Reference & \\
\hline Average & $1.102(0.612-1.983)$ & 0.747 \\
\hline Below average & $1.451(0.699-3.012)$ & 0.318 \\
\hline
\end{tabular}

$\mathrm{ADHD}$, attention-deficit hyperactivity disorder; OR, odds ratio; $\mathrm{Cl}$, confidence interval.

*Statistically significant difference. 


\section{DISCUSSION}

In this study, $5.7 \%$ of Korean college students were in the ADHD symptom group. These results are similar to the results of the U.S. College Student ADHD prevalence Study (2\%-8\%) [25] and the study "American Freshmen: National Norms 2010," which involved 201,818 people in 279 colleges and universities, showing 5.0\% (6.4\% men and $3.8 \%$ women) of students with ADHD [26]. On the other hand, the prevalence of ADHD in college students in Korea in this study was less than that reported in a previous Korean study (7.6\%) [14]. Therefore, a broader investigation of the prevalence of ADHD in Korea will be needed.

In adult ADHD, an evaluation of coexisting psychiatric diseases, such as depression, anxiety, and drug abuse, is important $[3-5,13,14]$. In this study, the prevalence of depression and anxiety was five times higher in the ADHD group than in the non-ADHD group. Even after adjusting for age, sex, and SES, the risk of coexisting depression in the ADHD group was more than four times higher. Hence, the comorbidity of depression in adult ADHD needs to be determined. Moreover, ADHD needs to be evaluated as an underlying disease of depressive college students.

The previous studies have reported that ADHD is related to addiction [27-29]. The present study identified problematic alcohol and internet use in ADHD and nonADHD groups. In previous studies, substance abuse, such as alcohol, has a high incidence in ADHD patients compared to the control group [30-32]. The results in this study did not reveal a significant difference in problematic alcohol use between the ADHD group and nonADHD group, but a numerically higher incidence was observed $(37.2 \%$ vs. $30.9 \%, p=0.242)$. These results are in line with the results of other studies on ADHD in college students in Korea, where problematic alcohol use showed a significantly high incidence [14].

In this study, pathological internet use showed a significant higher rate in the ADHD group. The pathological internet use also has a context of addiction. These results are consistent with the results of previous studies reporting a correlation between ADHD and internet addiction [1,5,10,11]. Individuals with ADHD tend to seek the stimulation and reward pathway [33]. Moreover, they have symptoms of 'being easily bored' and 'having an aversion for delayed reward,' and internet behavior gives them rapid response and reward [34]. Impaired inhibi- tion in ADHD also may result in difficulty in controlling internet use among individuals with ADHD [35].

In this study, the pathological internet use in the ADHD group showed a higher odds ratio than problematic substance use. These results suggest that in addition to the use of substances, such as alcohol, more attention to internet addiction may be needed in the addiction problem of adult ADHD. College students, as relatively young adults, can be exposed to the Internet for a longer period, which was accessible from childhood, and is likely to be pathological internet use in college students, particularly those with ADHD. Considering that the substance addiction of ADHD in adults was high in the previous study [30-32], the ADHD group in the present study is also likely to have more substantial problems with increasing age. In the future, a change in the addiction trend according to age in adult ADHD will need to be examined.

With respect to school grades and satisfaction, which can be related to the adaptation to college life, it will be necessary to examine why school dissatisfaction is significantly higher in the ADHD group, despite the similar grades. When referring to studies showing that ADHD is related to a difficulty in adjusting to college [7,8], dissatisfaction with school can lead to difficulty in school adjustment.

In this study, the ADHD group had a prevalence of $5.7 \%$, which was similar to that of children and adolescents. Compared to the non-ADHD group, the ADHD group showed a high incidence of depression, anxiety, pathological internet use, and dissatisfaction with their school. These results suggest that, like children and adolescents, there may be many hidden cases of ADHD in college students. Undiagnosed and untreated ADHD and depression can cause dissatisfaction with school life and a deterioration of function, which can lead to maladjustment to school. Therefore, early recognition and screening evaluation and assistance for adult ADHD should be made. In particular, ADHD, depression, and pathological internet use have an interactive correlation between those disorders [10-12]. If a college student has any of the above conditions or symptoms, it will be necessary to evaluate the possibility of other comorbidities and provide a detailed assessment of the psychiatric conditions.

This study had the following limitations. First, the causal relationship between ADHD and the related factors were difficult to address because this study was a 
cross-sectional study. Therefore, a prospective study will be needed to classify ADHD as a predictive factor for depression, anxiety, and pathological internet use. Second, this study investigated coexisting diseases, but did not make any differential diagnosis for each disease. There is a possibility that one disease symptoms could also be positive in the screening questionnaires of other diseases. Third, measures of ADHD and psychiatric symptoms were based on a self-report rather than a clinical evaluation. Lastly, this study was conducted on college students in a specific area. Therefore, generalizing the research results will be difficult.

\section{CONCLUSION}

These results showed that the prevalence of ADHD among college students was $5.7 \%$, which was similar to that of children and adolescents, and the risk of coexisting psychopathologies was high. Early screening, as well as a comprehensive psychiatric evaluation and intervention, will be needed for college students with adult ADHD to prevent the negative consequences, and help them adapt by increasing their satisfaction with school.

\section{CONFLICTS OF INTEREST}

The authors have nothing to disclose.

\section{ORCID}

\author{
Duk-Soo Moon \\ https://orcid.org/0000-0001-7878-3410 \\ Na Ri Kang \\ https://orcid.org/0000-0002-2086-0927 \\ Young-Eun Jung \\ https://orcid.org/0000-0001-7608-0009 \\ Moon-Doo Kim \\ https://orcid.org/0000-0002-6441-630X
}

\section{REFERENCES}

1. American Psychiatric Association. Diagnostic and statistical manual of mental disorders: DSM-5. Arlington: American Psychiatric Association; 2013.

2. Manicolo O, Grob A, Lemola S, Hagmann-von Arx P. Age- related decline of gait variability in children with attentiondeficit/hyperactivity disorder: support for the maturational delay hypothesis in gait. Gait Posture 2016;44:245-9.

3. Kessler RC, Adler L, Barkley R, Biederman J, Conners $\mathrm{CK}$, Demler O, et al. The prevalence and correlates of adult ADHD in the United States: results from the National Comorbidity Survey Replication. Am J Psychiatry 2006;163:716-23.

4. Strohmeier CW, Rosenfield B, DiTomasso RA, Ramsay JR. Assessment of the relationship between self-reported cognitive distortions and adult ADHD, anxiety, depression, and hopelessness. Psychiatry Res 2016;238:153-8.

5. Tateno M, Tateno Y, Kamikobe C, Monden R, Sakaoka O, Kanazawa J, et al. Internet addiction and attention-deficit/ hyperactivity disorder traits among female college students in Japan. J Korean Acad Child Adolesc Psychiatry 2018;29:144-8.

6. Yen JY, Yen CF, Chen CS, Tang TC, Ko CH. The association between adult ADHD symptoms and internet addiction among college students: the gender difference. Cyberpsychol Behav 2009;12:187-91.

7. Norvilitis JM, Sun L, Zhang J. ADHD symptomatology and adjustment to college in China and the United States. J Learn Disabil 2010;43:86-94.

8. Norwalk K, Norvilitis JM, MacLean MG. ADHD symptomatology and its relationship to factors associated with college adjustment. J Atten Disord 2009;13:251-8.

9. National Information Society Agency. 2014 A survey on internet addiction. Seoul: National Information Society Agency; 2015.

10. Dalbudak E, Evren C. The relationship of internet addiction severity with Attention Deficit Hyperactivity Disorder symptoms in Turkish university students; impact of personality traits, depression and anxiety. Compr Psychiatry 2014;55:497-503.

11. Kahraman Ö, Demirci EÖ. Internet addiction and attentiondeficit-hyperactivity disorder: effects of anxiety, depression and self-esteem. Pediatr Int 2018;60:529-34.

12. Saikia AM, Das J, Barman P, Bharali MD. Internet addiction and its relationships with depression, anxiety, and stress in urban adolescents of Kamrup district, Assam. J Family Community Med 2019;26:108-12.

13. Park S, Cho MJ, Chang SM, Jeon HJ, Cho SJ, Kim BS, et al. Prevalence, correlates, and comorbidities of adult ADHD symptoms in Korea: results of the Korean epidemiologic catchment area study. Psychiatry Res 2011;186:37883.

14. Kwak YS, Jung YE, Kim MD. Prevalence and correlates of attention-deficit hyperactivity disorder symptoms in Korean college students. Neuropsychiatr Dis Treat 2015;11:797802.

15. Yeom CW, Oh GH, Jung S, Moon JY, Son KL, Kim WH, et al. Prevalence and comorbidities of adult ADHD in male military conscripts in Korea: results of an epidemiological survey of mental health in Korean military service. Psy- 
chiatry Res 2020;293:113401.

16. Wang HR, Jung YE, Chung SK, Hong J, Ri Kang N, Kim $\mathrm{MD}$, et al. Prevalence and correlates of bipolar spectrum disorder comorbid with ADHD features in nonclinical young adults. J Affect Disord 2017;207:175-80.

17. Kim D, Lee D, Lee J, Namkoong K, Jung YC. Association between childhood and adult attention deficit hyperactivity disorder symptoms in Korean young adults with Internet addiction. J Behav Addict 2017;6:345-53.

18. Kessler RC, Adler LA, Gruber MJ, Sarawate CA, Spencer T, Van Brunt DL. Validity of the World Health Organization Adult ADHD Self-Report Scale (ASRS) Screener in a representative sample of health plan members. Int J Methods Psychiatr Res 2007;16:52-65.

19. Kessler RC, Adler L, Ames M, Demler O, Faraone S, Hiripi E, et al. The World Health Organization Adult ADHD SelfReport Scale (ASRS): a short screening scale for use in the general population. Psychol Med 2005;35:245-56.

20. Kroenke K, Spitzer RL, Williams JB. The PHQ-9: validity of a brief depression severity measure. J Gen Intern Med 2001;16:606-13.

21. Yoon S, Lee Y, Han C, Pae CU, Yoon HK, Patkar AA, et al. Usefulness of the Patient Health Questionnaire-9 for Korean medical students. Acad Psychiatry 2014;38:661-7.

22. Spitzer RL, Kroenke K, Williams JB, Löwe B. A brief measure for assessing generalized anxiety disorder: the GAD-7. Arch Intern Med 2006;166:1092-7.

23. Gordon AJ, Maisto SA, McNeil M, Kraemer KL, Conigliaro RL, Kelley ME, et al. Three questions can detect hazardous drinkers. J Fam Pract 2001;50:313-20.

24. Lee H, Ban J, Lee S, Choi Y, Lee S. Development of a self-report scale for measuring behavioral symptoms of adults' pathological internet use. Korean J Clin Psychol 2007;26:765-91.

25. Green AL, Rabiner DL. What do we really know about ADHD in college students? Neurotherapeutics 2012;9:55968.
26. Pryor JH, Hurtado S, DeAngelo L, Blake L, Tran S. The American freshman: national norms, Fall 2010. Los Angeles: Higher Education Research Institute; 2010.

27. Matthys F, Tremmery S, Autrique M, Joostens P, Möbius D, Stes S, et al. [ADHD and addiction: a complicated liaison]. Tijdschr Psychiatr 2012;54:539-48. Dutch.

28. Fatséas M, Hurmic H, Serre F, Debrabant R, Daulouède JP, Denis $\mathrm{C}$, et al. Addiction severity pattern associated with adult and childhood Attention Deficit Hyperactivity Disorder (ADHD) in patients with addictions. Psychiatry Res 2016;246:656-62.

29. Carpentier PJ. [Addiction from a developmental perspective: the role of conduct disorder and ADHD in the development of problematic substance use disorders]. Tijdschr Psychiatr 2014;56:95-105. Dutch.

30. Huntley Z, Young S. Alcohol and substance use history among ADHD adults: the relationship with persistent and remitting symptoms, personality, employment, and history of service use. J Atten Disord 2014;18:82-90.

31. Ohlmeier MD, Peters K, Te Wildt BT, Zedler M, Ziegenbein $\mathrm{M}$, Wiese $\mathrm{B}$, et al. Comorbidity of alcohol and substance dependence with attention-deficit/hyperactivity disorder (ADHD). Alcohol Alcohol 2008;43:300-4.

32. Biederman J, Wilens TE, Mick E, Faraone SV, Spencer T. Does attention-deficit hyperactivity disorder impact the developmental course of drug and alcohol abuse and dependence? Biol Psychiatry 1998;44:269-73.

33. Zametkin AJ. Dopamine reward pathway in adult ADHD. JAMA 2010;303:232-3; author reply 233-4.

34. Ko CH, Yen JY, Yen CF, Chen CS, Chen CC. The association between Internet addiction and psychiatric disorder: a review of the literature. Eur Psychiatry 2012;27:1-8.

35. Yen CF, Chou WJ, Liu TL, Yang P, Hu HF. The association of Internet addiction symptoms with anxiety, depression and self-esteem among adolescents with attention-deficit/ hyperactivity disorder. Compr Psychiatry 2014;55:1601-8. 